\title{
O "intelectual" segundo o pensamento decolonial de Walter Mignolo: redescrição e axiologia
}

\author{
FREITAS, Altiere Dias de ${ }^{1}$ \\ MORAIS, Jorge Ventura de ${ }^{2}$
}

\section{RESUMO}

Com base no pensamento de Walter D. Mignolo, o artigo visa esboçar uma "redescrição" de correntes tradicionais que tematizam a figura do "intelectual", tais como as "sociologias dos intelectuais" e o "pensamento pós-moderno". Intenta-se mapear aquilo que a perspectiva decolonial chama de "eurocentrismo" dessas contribuições. O argumento é que essa base epistemológica moderna, quando aplicada ao entendimento de intelectuais periféricos, apresenta limitações e problemas específicos. Além disso, na segunda parte do artigo, argumenta-se que a proposta alternativa de intelectual projetada por Walter Mignolo, vai além de fornecer novas ferramentas heurísticas. Busca instaurar um movimento de "desobediência epistêmica" que tem como ideal político reforçar processos de liberalização das experiências, memórias e histórias daqueles que foram silenciados pela colonialidade.

Walter D. Mignolo. Intelectual. Redescrição. Intelectual decolonial.

\section{The "intellectual" according to the Walter Mignolo's study on decolonial thinking: redescription and axiology}

Based on the thinking of Walter D. Mignolo, the article aims to outline a "redescription" of traditional currents that thematize the "intellectual" figure, such as the "sociologies of the intellectuals" and the "postmodern thinking". It attempts to map what the decolonial perspective calls the "Eurocentrism" of these contributions. The argument is that this modern epistemological basis, when applied to the understanding of peripheral intellectuals, presents specific limitations and problems. In addition, in the second part of the article, it argues that the alternative intellectual proposal designed by Walter Mignolo goes beyond providing new heuristic tools. It seeks to establish a movement of "epistemic disobedience" whose political ideal is to reinforce processes of liberalization of the experiences, memories and stories of those who have been silenced by coloniality.

Walter D. Mignolo. Intellectual. Redescription. Decolonial intelectual.

\footnotetext{
${ }^{1}$ Doutor em Sociologia pela Universidade Federal de Pernambuco; E-mail: altieredias@hotmail.com.

2 Professor Dr. do Programa de Pós-graduação em sociologia e do Programa de Pósgraduação em Música da Universidade Federal de Pernambuco; E-mail: venturademorais@gmail.com.
} 


\section{INTRODUÇÃO}

Se a "colonialidade", conceito central dos estudos póscoloniais/decoloniais latino-americanos, se reproduz fundamentalmente no nível "discursivo", "simbólico" e "linguístico", promovendo uma "colonialidade do saber", parte da resistência também se dá nesse nível ${ }^{3}$. Assim, a emergência de novos saberes e práticas exige a configuração de modalidades de atuação por parte daqueles que tradicionalmente se ocupam do conhecimento e da política, segundo vinculações diversas, acadêmicas ou não, os chamados "intelectuais". A discussão a respeito dos condicionantes, limites e potenciais da atuação do "intelectual" é um tema central para os estudos decoloniais/póscoloniais organizados a partir da América Latina ${ }^{4}$. Nesse corpus, cabe, talvez, a Walter Mignolo a perspectiva mais radical e fértil em termos de uma compreensão crítica e da proposição de novos paradigmas para atuação dessas tão controvertidas figuras.

É possível, a partir do auxílio das teses desse autor, revisitar o campo de estudos já consolidados que tomam o intelectual como objeto. Referimo-nos aqui à vasta e renovada reflexão a respeito da intelligentsia promovida pela sociologia. Outra importante referência a ser abordada são as perspectivas pós-modernas que apontam os limites do discurso universalista e das "grandes metanarrativas", algo que indica novos impasses na atuação do intelectual, tornando os fundamentos de sua ação/teorização bastante inseguros. Outro grupo de trabalhos interessantes sobre o intelectual veio do pensamento póscolonial ao colocar a questão do "Outro" no contexto colonial, denunciando o caráter não transparente, eurocêntrico, universalista, provinciano e epistemicamente violento das tradições disciplinares do pensamento racional.

Nesse contexto, o objetivo do artigo é, em um primeiro momento, tomando a abordagem decolonial de Mignolo como fundamento, apontar os limites dessas perpectivas sociológicas, pós-modernas e pós-coloniais para a compreensão do intelectual em um contexto de colonialidade. A ideia é fazer aquilo que Rorty chamou de "redescrição", valendo-nos das ideias de

\footnotetext{
3 "Se a colonialidade do poder se refere à inter-relação entre formas modernas de exploração e dominação e a colonialidade do saber tem a ver com o papel da epistemologia e das tarefas gerais da produção do conhecimento na reprodução dos regimes coloniais de pensamento, a colonialidade do ser se refere, então, à experiência vivida da colonização e seu impacto na linguagem" (MALDONADO-TORRES, 2007, p. 130).

4 Ver, por exemplo, as contribuições de Castro-Gómez (2005), Martins (2010) e Santos (2010).

5 No "Contingência, ironia e solidariedade" Rorty afirma que o ironista habita a tradição inaugurada por Hegel (1989, p. 78), que através da dialética procedeu não a uma argumentação, mas sim a criação de um vocabulário novo, portanto de um novo "objeto", superando o que era obsoleto. Nessa perspectiva, o "filosofar" é, através de uma dialética, a aplicação e o desenvolvimento de um novo vocabulário, mais do que a reflexão a respeito de realidades externas e fenômenos importantes, aproximados através da lógica argumentativa. Segundo Rorty, com as contribuições de Nietzsche, Heidegger e Foucault, entre outros. $O$ autor afirma que o ironista percorre distintos vocabulários, jogando uns contra os outros, procedendo "redescrições" (1989, p. 80), comparando segundo seus objetivos, reinscrevendo
} 
corpopolítica (MIGNOLO, 2011, p. 140) e geopolítica do conhecimento (MIGNOLO, 2011, p. 119) de Mignolo para esboçar uma crítica das referidas tradições de estudo que colocam o intelectual em um patamar de análise. $\mathrm{Na}$ perspectiva decolonial, tal redescrição incluiria reenraizar as ideias no solo da experiência biográfica, corpórea, que possui certas disposições, imaginário, gramática de práticas, línguas e culturas específicas (MIGNOLO, 2011, p. 113).

Em uma segunda parte, delinearemos o modo como Mignolo concebe a atuação de um "intelectual" que, unindo a verve crítica e analítica do acadêmico e a organicidade de um militante envolvido em suas comunidades, promoveria a "desobediência epistêmica" (MIGNOLO, 2010, p. 17) e a emergência de novos saberes. Assumimos a ideia de Karabel (1996) que diz existir uma corrente axiológica do estudo sobre os intelectuais que os tratam "não como eles realmente são, mas como devem ser". Dessa forma, tal tradição moralista "fornece, em resumo, uma forma de referência idealizada para pensar sobre os intelectuais ao invés de uma instância empiricamente baseada e analítica" (KARABEL, 1996, p. 205). Veremos que o ideal de intelectual de Mignolo parece ser uma proposta bastante útil para estudos acadêmicos e a práxis de movimentos sociais e culturais envolvidos em processos de resistência a colonialidade, apesar de alguns limites.

\section{Sociologias dos intelectuais}

A "sociologia dos intelectuais" possui uma importante história que pode ser retraçada, em termos de uma narrativa focada no "ocidente", às primeiras impressões e autocompreensões a respeito dos dreyfusards, o grupo de intelectuais de apoio ao capitão Dreyfus. No entanto, a robustez do corpus nem sempre foi a mesma. Seu grau de coerência e vigor oscilaram tanto quanto as compreensões em relação ao seu objeto de estudo. Essa própria instabilidade, com os intelectuais às vezes enquadrados como uma "classe em si", como vinculados a classes específicas ou parcialmente dependentes de grupos, gerou diversas tradições: ora focadas na emergência e funcionamento desse grupo social, tal como Bourdieu; ora focadas em sua "organicidade" e dependência, como nas abordagens gramscinianas; ou ainda perspectivas que dizem sobre seu caráter arredio e independente. A referência desse último grupo é Mannheim (MANNHEIM, 2013; KURZMAN \& OWENS, 2002). Não é à toa que muitas vezes a sociologia dos intelectuais recaiu em uma perspectiva normativa que procurava depurar os elementos paradoxais, as incoerências e os problemas que a atividade pública dos intelectuais coloca (KARABEL,

elementos de um em outro, sem conceber nenhum como privilegiado, como ancorado em algum fundamento não humano. 
1996). Muito embora, pensando a partir da abordagem decolonial, as diferenças existentes em tais perspectivas podem ser vistas como secundárias ao pensar em sua vinculação à episteme "ocidental", sua perspectiva universalista provinciana e os limites que possuem ao referir-se à experiência dos intelectuais localizados nas margens do sistema mundo.

Em sua seminal análise, Gramsci procura definir o intelectual não de acordo com os elementos "espiritual e mental", intrínsecos a sua atividade, mas sim segundo o lugar que ocupa em uma dada ordem social, especialmente a moderna. Afirma que todo grupo social "cria para si (...) uma ou mais camadas de intelectuais que lhe dão homogeneidade e consciência da própria função" (GRAMSCI, 1989, p. 3). Portanto, o "intelectual orgânico" (GRAMSCI, 1989, p. 10) estaria necessariamente vinculado a uma posição política e social no contexto conflituoso do capitalismo. Diferentes deste, os "intelectuais tradicionais", originários de uma ordem pré-capitalista, colocam-se a si mesmos, de forma idealista, como autônomos e independentes dos grupos sociais dominantes. Dentro da perspectiva contra-hegemônica do autor italiano, existe o diagnóstico de uma correlação de forças dominadas por intelectuais orgânicos das classes dominantes, formuladores de "consenso social". Ao mesmo tempo, fala do potencial que intelectuais orgânicos ligados às classes populares teriam para provocar uma ruptura no status quo e, através de uma luta cultural e política, promover os interesses e visões de mundo conformados nessas classes (DEL ROIO, 1998, p. 115). Essa conceitualização, já clássica, fundamenta uma abordagem chamada "valorativa" dos intelectuais, além de potencializar uma sociologia crítica, baseada na ideia de práxis.

Mignolo elogia a ideia de "subalterno" em Gramsci, termo que não se refere apenas à classe trabalhadora da revolução industrial, mas sim "a todos cujos progressos de tal revolução criaram condições que os deixaram fora do jogo" (MIGNOLO, 2005, p. 385). É clara a influência da concepção de organicidade, presente na ideia gramsciana de intelectual, no modo como o autor argentino projeta os intelectuais como "aqueles que se destacam por sua contribuição para a articulação do imaginário de uma comunidade" (MIGNOLO, 1997, p. 1140). No entanto, como típico de seu pensamento, o autor argentino aponta que a conceitualização de Gramsci, na encruzilhada entre a tradição intelectual ítalo-latina e socialista (MIGNOLO, 2005, p. 381), nasceu a partir de um local específico, o Sul da Europa e de problemas locais. Seria, assim, cega em relação à experiência social e política de outras partes do mundo (MIGNOLO, 2005, p. 385). Além do mais, assumindo essa crítica decolonial, é possível pensar a versão gramsciana do intelectual como projetada segundo um esquema universalista e, em certo sentido, linear, opondo formas mais tradicionais e outras mais modernas de sua manifestação. A autossuficiência com que Gramsci faz o diagnóstico mundial desde sua prisão europeia, em certo sentido, condenando o modo atrasado como a figura do intelectual se manifestava em outros lugares, parece evidenciar essa leitura livre, 
generalizante e dual típica da epistemologia criticada pelo pensamento decolonial (GRAMSCI, 1989, p. 22).

Tradicionalmente, a abordagem dessa controvertida e opaca figura se realiza em nossa disciplina também a partir de perspectivas sociológicas mais "científicas". Dentre essas, destaca-se a análise "ideológica" fundada no clássico estudo mannheiminiano da ideologia em seu sentido geral e restrito (MANNHEIM, 1986). Superando uma história das ideias reificada, bem como respondendo à necessidade de um conhecimento que dê conta do estilhaçamento de perspectivas surgidas com a modernidade, Mannheim promoveu uma "sociologia do conhecimento" baseada na compreensão da vinculação existencial de qualquer ideia. Seria possível atribuir a uma "posição social" a conformação de determinadas maneiras de conhecer e conceber a realidade que são animadas pelos intelectuais. Embora, diferentemente da quase necessária dependência em relação aos grupos sociais vista por Gramsci, Mannheim parece dizer que existe em todo intelectual um "traidor". Eles podem forjar alianças temporárias ou mesmo mais orgânicas com os interesses de classe, mas, por serem dotados de pontos de vistas diferentes para encarar a realidade, apresentam o caráter de ser menos "confiáveis", dispostos a mudar de opinião ou a abandonar uma causa (MANNHEIM, 2013, p. 81).

Aqui não há uma avaliação moral. Mannheim insinua que, apesar de 0 intelectual poder descansar sobre uma dada perspectiva e até mesmo enrijecer-se como funcionário de algum partido, o caráter não fundacional do conhecimento e sua ética de trabalho, crítica, racional e avaliativa, o levava a permanecer, pelo menos potencialmente, independente. Uma versão "degenerada" dessa tendência seria o culto ao conhecimento "esotérico" (MANNHEIM, 2013, p. 91). É a manifestação de uma relação incestuosa, asséptica, que o intelectual contemporâneo teria com o conhecimento, na medida em que sua posição institucional universitária estava garantida. Algo que, em outro contexto, Williams James (1921) chamara de "racionalismo" exacerbado. Seus adeptos, confiando em sistemas explicativos, apriorísticos que dão acesso ao sentido último do mundo, solapariam, na verdade, qualquer insight em relação ao caráter caótico, assistemático, contingencial da vida cotidiana. O que fica dessa abordagem mannheiminiana é o aviso sobre como a prática do intelectual, apesar de poder ser de importância pública, ideológica, tem como alvo uma certa "autorreprodução" ou uma ética de trabalho que nem sempre nem necessariamente se confunde com a posição política assumida.

Críticas usuais a essa perspectiva incluem sua reduzida capacidade operativa, ao não especificar as diferentes maneiras que diferentes conhecimentos são produzidos, algo que deu base ao refinamento feito por Merton (2013). Além disso, sua noção ampla de ideologia parece ainda estar presa de um impulso avaliativo epistemológico que soa paradoxal: cava um lugar privilegiado e indeterminado para julgar outros conhecimentos, sempre 
concebidos como socialmente vinculados (RODRIGUES, 2005). Mas foi justamente o contexto alemão da década de 1920 que originou os particulares problemas para os quais a "sociologia do conhecimento" deu respostas, que nem sempre foram deglutidos de forma fácil em um contexto diferente como os EUA (BERGER \& LUCKMANN, 2007, p. 15). De fato, a leitura de cima, distanciada, realizada por Mannheim, parece recair na adoção daquilo que Castro-Gómez chama de Hibris de punto zero (2005), um espaço epistêmico autolegitimador, cego a seus lugares de fala. Além disso, apesar de esforçar-se por considerar distintas formas de "conhecimento", Mannheim se concentra no conhecimento acadêmico, racional, desprezando a possibilidade da realização daquilo que Mignolo chamou de uma gnosiologia (MIGNOLO, 2003, p. 35).

Uma outra forma de enquadrar o intelectual é a análise de sua estrutura organizacional e institucional. Uma abordagem bourdieusiana das trajetórias dos sujeitos, de sua função no mercado de bens simbólicos ou a estrutura de gosto que demonstram ao exprimir suas "escolhas" é o fundamento de muitos estudos nessa área (LECLERC, 2005). Interessante é que Bourdieu percebe, de forma bem mais elaborada que Mannheim, essa tendência ao "distanciamento" existente na atividade do intelectual. Seu "campo científico", onde o funcionamento optimum seria a concorrência entre agentes com base em pressões puramente científicas, é caracterizado por um processo de "refração" diante de demandas externas (BOURDIEU, 2004, p. 22). Essa força centrípeta atua também quando um intelectual buscaria dar conta da "condição operária segundo esquemas de percepção e apreciação diferentes" dos atualizados pelos próprios membros das classes populares (BOURDIEU, 2013, p. 350). Bourdieu insinua que isso é uma forma de colocar essas classes populares à distância, constituindo-as em objeto de contemplação, de comiseração, de indignação, uma forma de proximidade distante e de nostalgia populista.

Assim, essa perspectiva alerta que muitos trabalhos que tematizam "as classes populares" aparecem mais como uma tomada de posição no campo intelectual do que um retrato de uma existência orgânica em si mesma ou de uma real tentativa de diálogo. O que talvez seja a maior fraqueza dessa compreensão da relação entre intelectual e "classes populares" é uma, mais ou menos explicita, visão negativa dessas últimas, caracterizadas, sobretudo, por sua privação e necessidade (BOURDIEU, 2013). O olhar que Bourdieu dirige para o "popular" é condicionado pela compreensão de uma situação de desigualdade na qual aqueles que estão na base da pirâmide não tem espaço para a criatividade, para produzir uma cultura assentada em um novo patamar de valoração, que escape à cultura legitima. O modo como estrutura sua pesquisa parece impedir um aprofundamento nos universos, diria Mignolo, silenciados, que as falas dos "homens simples" podem revelar. Por isso mesmo, assumindo essa postura decolonial, acreditamos ser preciso ampliar a 
compreensão do que é um conhecimento e manifestações culturais válidas, em uma epistemologia que dê conta do conhecimento local, não sistemático.

Connell (2006) afirma que, apesar de seu amplo mergulho no "Sul", a obra de Bourdieu não deixa de se enquadrar em uma tradição "eurocêntrica": se afirma a partir de um universalismo e de gestos de exclusão e apagamento em relação à experiência social e a produção intelectual não europeia. Segundo essa perspectiva, Bourdieu acaba adotando um pressuposto de homogeneidade da história humana, que poderia ser enquadrado a partir de um esquema de análise que se concentra na "reprodução social". Sua concepção de ator, que usa barganha em um mercado, é projetada em campos aparentemente não ajustados a essa visão. Outra crítica é que ele realiza uma "grande etnografia", justificando a caracterização de tipos de sociedade prémodernas e modernas, que é típica da teoria social feita no "Norte". Connell usa como ilustração das características desse tipo de teoria o fato de Bourdieu lidar com a situação colonial argelina, sem sequer ter o trabalho de ler autores não europeus, como Fanon, que estavam vivendo e pensando diretamente com aquela realidade (CONNELL, 2006, p. 257).

Assim, em uma dimensão epistêmica, observa-se nessas abordagens sociológicas, a atualização daquilo que Mignolo chama de "epistemologia monotópica da modernidade" caracterizada por um universalismo provinciano e algo como um esquema linear da história, "cuja vitória foi possibilitada por seu poder de subalternizar o conhecimento localizado fora dos parâmetros das concepções modernas de razão e racionalidade" (MIGNOLO, 2003, p. 103). Esse pensamento "abissal" (SANTOS, 2007), produzido em países imperialistas Europeus como França, Itália e Alemanha, a partir das histórias memórias e línguas específicas, projeta noções sobre o intelectual sem levar em conta os terríveis dilemas da colonialidade. Adotar o ponto de vista decolonial, significa, então, apontar tais perspectivas como tautológicas, negadoras de outras formas de conhecimento e cegas aos efeitos perversos do colonialismo, que trazem um contexto distinto para perceber a atuação de uma intelligentsia periférica.

\section{Pós-modernismo: intelectuais ansiosos}

Em relação aos estudos contemporâneos que colocaram outras questões à atuação do intelectual, um importante corpus foi gestado no ambiente intelectual francês. Aqui, uma contribuição importante refere-se ao crescente questionamento e ceticismo, diagnosticado por Lyotard, em relação às grandes "metanarrativas" que representaram os elementos fundacionais do conhecimento em grande parte do século XX. O autor francês explora a organização dos saberes nas sociedades contemporâneas desenvolvidas. 
Lyotard argumenta que existiria uma difusão da compreensão da arbitrariedade dos sistemas de conhecimento, aliada a um questionamento dos alicerces das formas modernas de conhecer. A autoridade para lançar julgamentos em relação a qualquer assunto não dependeria mais de uma fonte transcendental de verdade, mas sim de um conjunto de regras locais que governariam um discurso particular, um "jogo de linguagem" (LYOTARD, 2009, p. 16).

Lyotard anuncia, assim, no "A condição pós-moderna" (2009), que o "pós-moderno, enquanto condição da cultura contemporânea caracteriza-se exatamente pela incredulidade perante o metadiscurso filosófico-metafísico" (LYOTARD, 2009, p. VII). Refere-se especialmente à metanarrativa do sujeito transcendental, do espírito universal, que marcha em direção a um fim unitário da história e do sujeito, a uma emancipação baseada na razão e no progresso. Esses construtos estabeleceram os pressupostos fundantes da filosofia iluminista e orientam a tradição marxista e sua pulsão "totalizante". O conhecimento científico, no argumento de Lyotard, também se baseia em mitos e histórias heroicas para se legitimar. Contra essa reificação, Lyotard propõe uma "ciência pós-moderna" preocupada com elementos de incerteza, limites de controle, paradoxos, performance, que recuperaria outras perspectivas que foram marginalizadas pela razão moderna (LYOTARD, 2009, p. 108). O fato é que, como coube sempre aos intelectuais a tessitura ou, no mínimo, a propagação dessas grandes histórias, quando os fundamentos para os mitos de progresso e civilização são solapados, também há uma corrosão do papel do intelectual "tradicional". Em certo sentido a crítica de Mignolo também se refere à dissolução dos fundamentos a partir dos quais uma intelligentsia projetava os sentidos do mundo e, como saída, propõem uma "decolonial scientia"6.

Mignolo, no entanto, argumenta contra essa perspectiva que não se pode demarcar uma "sucessão linear de períodos". Aponta, ao contrário, a existência de aglomerados históricos, a coexistência de um lado "elogioso", "defensável" da modernidade, da mesma forma que um darker side (MIGNOLO, 2011). Essa experiência colonial escaparia a perspectivas pósmodernas como a de Lyotard. Esse "intelectual do primeiro mundo" realizaria a "crítica da razão" a partir do centro imperial, caindo no paradoxo de legislar uma visão regional como universal. Mignolo, com Dussel, busca propor "uma crítica aos movimentos irracionais do iluminismo como mito sacrifical, não através da negação da razão, mas afirmando a razão do outro" (MIGNOLO, 2003, p. 168). Da mesma forma que o pensamento pós-moderno alega construir um pensamento contramoderno, o pensamento decolonial busca um pensamento anticolonial a partir de uma "gnosiologia limiar" (MIGNOLO, 2003). Além disso, ainda do ponto de vista decolonial, Lyotard não conseguiria

6 "A ciência decolonial não é a ciência do progresso e do desenvolvimento, mas sim a base para liberar as atuais e as futuras vítimas do conhecimento, sobre as quais o progresso e o desenvolvimento são impostos" (MIGNOLO, 2011, p. 112). 
abarcar em sua análise os problemas específicos que a imposição da colonialidade trouxe para intelectuais que habitam um lócus de enunciação fora dos centros imperiais, ou seja, que atuam a partir de heranças coloniais em "territórios que hoje constituem certos países da América hispânica" tais como, alegadamente, o próprio Mignolo (MIGNOLO, 2003, p. 155).

Voltando à França, Foucault é outra importante referência. Tal como a de Lyotard, sua teorização nasceu em um contexto pós-maio de 1968, época de notáveis transformações sociais que colocaram questões e aprofundaram outras relativas ao meio-ambiente, ao lugar das minorias, das mulheres, etc. Portanto, época fértil na recepção a discursos questionadores da autoridade e dos valores conservadores. Com uma nova cultura política, houve mudanças permanentes na expressão do ser intelectual e a exigência de um tipo diferente, trabalhando na contingência dos "jogos de linguagem", em contextos sociais e políticos específicos e dotado de elevada reflexividade. Foucault centra alvo no intelectual heroico, paladino dos universais e das evidências, que diz a "verdade àqueles que ainda não a viam e em nome daqueles que não podiam dizê-la" (FOUCAULT, 1979, p. 71). Sua própria trajetória foi marcada por uma postura cética em relação às grandes palavras, os "universais", além de uma permanente busca em evitar a adoção de um papel de sacerdote da verdade. Mas, ao mesmo tempo, foi criador de um importante sistema teórico, se engajou em lutas sociais, tendo sua obra como fonte de reflexão e práxis. Ribeiro afirma que Foucault conseguiu não apenas se afastar de um "sistema fechado", dos "poderes constituídos", mas também "das ideias constituídas" (RIBEIRO, 1995, p. 172). Já Rorty, elogia o "historicismo" de Foucault, muito embora afirme que o autor francês recaiu em algo como uma "postura metafísica" (RORTY, 1989, p. XII).

O fato é que, em sua crítica ao "humanismo", Foucault acaba atacando o que caracteriza como aquele que é portador de "quimeras", de "ficções" animadas por um sujeito de conhecimento que se julga detentor da verdade, da justiça, discursando em nome do proletário (FOUCAULT, 1994). Chama esse tipo, de forma caracterológica, de "intelectual universalista", encarnado em sua forma mais radical na figura de Zola, que tem na sua notoriedade um dos fundamentos principais de sua ação/criação (GODIN 2014, p. 176). Oposto a esse, o autor francês caracteriza o "intelectual específico" que, vinculado a pontos particulares no mundo social (profissão, região geográfica, gênero, etc.), desenvolve suas reflexões e ações a partir de problemas específicos e localizados, partindo do particular para dialogar com outros atores e com outras questões políticas. Tais intelectuais específicos se aproximariam, em certo sentido, das massas, atuando na vida cotidiana, "real" e material. Eles enfrentariam, por vezes, os mesmos adversários que o proletariado enfrentava, tais como "as multinacionais, o aparelho jurídico e policial, a especulação imobiliária" (FOUCAULT, 1979, p. 9). Para incorporar esse novo ideal, Foucault se dispôs a deixar de lado a escrita literária e a especulação, em favor da 
atividade "prática", engajando-se, nos anos 1970, no Grupo de Informação Sobre as Prisões (GIP). Buscou assim "um trabalho efetivo" ao invés da "parolagem universitária e da escritura livresca" (GODIN, 2014, p. 182).

No entanto, de um ângulo decolonial, tal enquadramento foucaultiano pode ser problemático. Nos referimos às dificuldades relativas à "cegueira colonial" (MIGNOLO, 2003, p. 44) também apontadas em Lyotard, ou seja, ao fato de que Foucault concebeu sua tipologia ao lidar com os problemas, contextos e herança intelectual interna à Europa ${ }^{7}$. Ao aplicar o esquema de Foucault aos intelectuais em contexto de colonialidade, corre-se o risco de adotar um lugar de fala imperial. Além do mais, a dualidade implícita no esquema "universal" $X$ "específico" pode levar a uma perspectiva arrogante que, de partida, assume sua própria postura como superior ("mais livre" da afirmação de mecanismos de poder) que a estudada. A teorização de Mignolo, muito influenciada por esse "pensamento francês", navega nesse espaço perigoso, procurando evitar uma epistemologia universalista, eurocentrada, especialmente através da ideia de uma composição política e geopolítica do conhecimento.

Mas, apesar desse reconhecimento, Mignolo afirma que os próprios pensadores que apontavam para a desagregação do pensamento ocidental e fizeram uma crítica contundente de suas bases, como Foucault (2003, p. 172), Deleuze e Guattari (2003, p. 116) e Derrida (1995, p. 319), ainda permaneceram dentro de uma epistemologia que deveria ser superada. $O$ fato é que suas soluções aparecem como "universais" e, ao se mostrarem cegos à diferença colonial, reproduzem a lógica de afirmar uma razão vinculada a uma história local como se fosse desenraizada. O autor diz que Nietzsche, por exemplo, fez a crítica do ocidente dentro da metafísica ocidental (MIGNOLO, 2003). Uma crítica marginal ao pensamento eurocêntrico, nessa perspectiva, não pode ser universal, pois deve partir de outras experiências, outras metafísicas, de outras histórias. Da mesma forma, Mignolo diz que uma crítica comum a sua obra é o não reconhecimento daquelas fontes francesas como, por exemplo, a constatação de realizar um "nomandismo" tal como Deleuze e Guattari sem reconhecê-lo. Defende-se afirmando que, de fato, é influenciado por esses autores, mas alia seu potencial crítico à assunção da diferença colonial, da história e da experiência do pensamento fronteiriço.

Entre outros desenvolvimentos dessa crítica francesa, em oposição às macroteorias distanciadas, ocorreu uma ênfase nos elementos subjetivos e

\footnotetext{
7 "Europa" é considerada como lugar de fala, ou seja, espaço não ontológico que pode e é assumido por pessoas que vivem em culturas periféricas. Foucault aqui é uma referência central. Em livros como "As palavras e as coisas" (2007) e "Arqueologia do saber" (2015), procura mapear a reafirmação de ordens epistemológicas, determinadas geograficamente e culturalmente, que legitimam uma evolução social específica, a ocidental. É nessa base, procurando superá-la, que Mignolo desenvolveu a ideia de "lócus de enunciação". Ver, por exemplo, Mignolo (2001, p. 172); (2007, p. 41) ou (1995, p. 4).
} 
pragmáticos da construção do conhecimento. Elevou-se a um patamar de importância elementos identitários e sociológicos como raça, etnicidade, gênero e sexualidade, ao lado dos tradicionais marcadores de classe e nacionalidade para compreender a construção dos saberes/poderes na vida social. A "política de identidade", um neologismo para o termo em inglês "identity politics" (HEYES, 2018), refere-se a uma ampla gama de intervenções práticas e teóricas, cujo fundamento é a posição de resistência à opressão e a expressão de perspectivas identitárias particulares como premissas fundamentais do conhecimento. Nesse contexto, parece ser um imperativo moral a fundamentação de uma "organicidade contra-hegemônica" para atividade e teorização do intelectual (FUREDI, 2003). Sem a qual essa figura aparece como um representante de um conservadorismo social e perpetuador de desigualdades, mesmo que deseje o contrário. Tal exigência é um elemento fundamental do pensamento decolonial.

\section{Pós-colonial e a denúncia do colonialismo intelectual}

Outra vertente que problematizou os dilemas vividos pela intelligentisia são as teorias pós-coloniais. Aimé Césaire foi, em 1950, um dos primeiros a lançar a questão do "colonialismo intelectual" que ainda hoje ecoa nos estudos culturais, mas também no pensamento decolonial. $\mathrm{Na}$ análise realizada em seu "Discurso contra o Colonialismo" (CÉSAIRE, 1978), busca superar uma abordagem economicista vulgar, denunciando a existência de uma ideologia racial difusa. Aponta que, por trás da europeização dos países colonizados, existiria uma ordenação racista que, oculta no discurso salvacionista, legitimava a expropriação e a humilhação dos povos colonizados. Afirma que a baixa estima do negro, vítima de uma alteridade imposta, é plasmada nessa estrutura verdadeiramente bárbara (CÉSAIRE, 1978, p. 21). Ou seja, Césaire faz uma importante operação: inverte a ideia de barbárie, apontando tal pecha para o próprio colonizador. Uma operação de grande valor em seu argumento é vincular a manutenção dessa estrutura colonizadora ao trabalho dos "cães de guarda do colonialismo" (CÉSAIRE, 1978, p. 40), os intelectuais. Amoitados em seus limites disciplinares, sob o valor da "racionalidade", da objetividade "científica" e do "universalismo", sociólogos, psicólogos, historiadores, jornalistas, etc., promoveriam ideias que contribuíam para a justificação da violência colonial (CÉSAIRE, 1978, p. 41).

Ao denunciar tal situação, Césaire se dirige a uma intelligentisia europeia, mundial, buscando instaurar uma ferida narcísica. Fala também aos "irmãos negros", instilando resistência contra uma dominação intelectual que impediria uma tomada de consciência das elevadas capacidades dos povos submetidos à colonização. "O Discurso" foi concebido como um grito de liberdade, influenciado pelo contexto de lutas de libertação na Ásia e na África. 
Tornou-se, segundo Mário de Andrade, o "livro vermelho dos militantes, fossem eles professores primários, jovens, funcionários, sindicalistas ou intelectuais" (CESAIRE, 1978, p. 8). E apesar da necessidade de um novo olhar crítico, em seu escrito, Cesaire não nega a "Europa" de forma implacável. O problema para ele foi que o contato ocorreu de forma violenta, dominadora, como "colonização" e não "civilização" (CESAIRE, 1978, p. 15). Aqui, Césaire parece deixar transparecer um "pensamento linear", ainda crente nos efeitos da modernização, do humanismo iluminista, separando o lado elogioso da herança europeia de seu darker side (MIGNOLO, 2011), Dissociação que, segundo a crítica decolonial, seria impossível de fazer. O discurso, contudo, é um ataque feroz, visceral, às instituições da colonização, surgido de uma sensação de injustiça e pode ser incluído em uma genealogia das origens do pensamento decolonial que, segundo Mignolo, forma a base de um "pensamento distinto" (MIGNOLO, 2011, XII).

A teorização de Frantz Fanon parte dessa mesma constatação dolorosa do lugar danoso que o "negro" ocupa vis-à-vis o "branco". Suas ideias também não eram uma mera reflexão acadêmica dos efeitos desintegradores do colonialismo, na medida em que o autor viveu diretamente tais consequências. Seus livros "Em defesa da Revolução Africana" (1980) e "Los degredados de la tierra" (2001) foram gestados sob o impacto da feroz luta anticolonialista que testemunhou e realizam uma tomada de posição a favor da causa argelina que ainda repercute na "leitura francesa" sobre 0 autor ${ }^{8}$. Mas, talvez, o livro de maior interesse aqui seja o "Peles negras, máscaras brancas" (2008), em que o autor, através de uma "sociogênese" (FANON, 2008, p. 28), procura diagnosticar os efeitos perversos do racismo a partir da experiência martiniquense. Analisando elementos tão diversos quanto peças de publicidade, casos clínicos, romances, poesias e livros didáticos, Fanon destrincha a dialética "colonizador-colonizado". Procura uma saída para os narcisismos que prendiam o negro e o branco em posições autorreferidas e que corroíam a possibilidade de uma relação aberta, construtiva e humana. Em um tom existencialista, Fanon mostra os desafios que o negro, preso entre uma negritude negativa imposta e uma positivação ceseiriana reificante, enfrenta na busca de afirma sua existência.

Fanon também critica o intelectual propagador de ideologia, como no caso do psicanalista francês Octave Mannoni (FANON, 2008, p. 84). Contudo, mais do que atacar os que ele coloca como propagandistas do colonialismo, 0 que Fanon procura realizar no livro é a superação de teorias eurocêntricas. Para o autor, o conflito, a neurose no negro, surgiria sob o peso do "olhar do branco" e não a partir de elementos inconscientes conformados em instituições europeias, tais como os descritos por Freud, Adler e Jung (FANON, 2008, p.

\footnotetext{
${ }^{8}$ Cherki, Alice. Frantz Fanon, l'anticolonialiste. Disponível em < https://www.youtube.com/watch?v=6hE_yHEduUk\&t=12s>Acessado em: 10 de setembro de 2017.
} 
127). Mesmo utilizando teorias vindas da Europa, Fanon as submete à resolução dos dilemas vividos pelos negros, ele incluído. Esse estilo de teorização e prática intelectual, desobediente, visceral, foi elevado ao status de ideal pelo pensamento decolonial, cristalizado na ideia de "desobediência epistêmica" e "pensamento limiar". Embora, diferentemente do pensamento decolonial, Fanon não tem problema em adotar uma posição universalista e humanista como proposta de superação das armadilhas da colonização. Além de reconhecer que, mais do que um problema do intelectual negro, esse dilema racial atinge o negro explorado em seus universos cotidianos, colocado em posições de subalternidade pelo racismo ${ }^{9}$. Isso aponta para uma particularização dos modos como a colonização atinge diferentes grupos e a existência de diferentes formas de resistência e integração à colonialidade. Intuição importante para quando a obra de Mignolo for abordada em seus detalhes.

Mas, nesse grupo, talvez tenha sido Edward Said quem teorizou de uma forma mais bem-acabada uma estrutura de "saber-poder" de origem eurocêntrica que condiciona a atividade intelectual e contribui para a perpetuação da dominação colonial. Na obra "Representações do intelectual" (1994), criou uma viva imagem desse ator público que "falava a verdade para o poder" (SAID, 1994, p. 97). Projeta um intelectual crítico, capaz de questionar os "nacionalismos patrióticos, o pensamento corporativo e os privilégios raciais, de gênero e classe" (SAID, 1994, p. 13). Entre os perigos contemporâneos para sua atuação estariam a tendência a uma especialização exagerada, ao culto da expertise e dos diplomas, e às pressões para se render aos poderes constituídos. Chama a atenção a ideia de que uma exagera "profissionalização" levava os intelectuais para longe de um salutar "amadorismo" (SAID, 1994, p. 83). Posição muito compreensível de quem fez carreira em uma prestigiosa universidade, bebendo da fonte "ocidental", mas que procurou manter-se ativo como um intelectual público, envolvendo-se com a causa palestina. Além de teoricamente, em livros como "Cultura e Imperialismo" (2011), denunciar as simbólicas e sangrentas violências do imperialismo.

Não é à toa que "Orientalismo" (2007) de Said é considerado um dos livros fundantes do "pós-colonialismo" ao pôr em evidência uma maneira de apreender o mundo que, enunciada a partir do ocidente, instaura uma fratura em relação ao seu oposto inferior, o "oriente". Nesse retrato, um conjunto amplo de conhecimentos aparece como parte de uma estrutura discursiva que atualiza uma divisão binária fundante, o "mesmo" versus o "outro". Said

\footnotetext{
${ }^{9}$ Fanon afirma que "é evidente que o esforço de desalienação do doutor em medicina de origem guadalupense se faz compreender a partir de motivações essencialmente diferentes daquelas do preto que trabalha na construção do porto de Abidjan. Para o primeiro, a alienação é de natureza quase intelectual. Na medida em que concebe a cultura europeia como um meio de se desligar de sua raça é que ele é um alienado. Para o segundo, é como vítima de um regime baseado na exploração de uma raça pela outra, no desprezo de uma parte da humanidade por uma civilização tida como superior" (FANON, 2008, p. 185).
} 
demonstra que os intelectuais, propagadores de tais discursos, ajudam a perpetuar um modo institucionalizado de compreensão que teria consequências políticas diretas. No caso das ciências humanas, como bem estudou Stuart Hall, tal interpretação levou à crítica dos valores ocidentais que estão em seus fundamentos (1992). Uma das consequências dessa obra de Said é colocar a tarefa da construção de novas formas de conhecimento que dialoguem com vozes distintas ou que promovam saberes alternativos.

Essa suspeição diante dos "discursos ocidentais" e a busca de um conhecimento desobediente, forjado na dolorosa experiência de racialização dos povos e regiões, permite imaginar uma nova prática intelectual crítica e militante. É clara a apropriação que Mignolo fez desse estilo de teorização, ao realizar sua "geografia do conhecimento", mostrando que tal epistemologia ocidental, com suas divisões imperialistas, tocou de maneiras distintas os diversos lugares periféricos submetidos à colonialidade (MIGNOLO, 2003). Mas, apesar da importância do pensamento pós-colonial, Mignolo afirma que as reflexões de autores como Said, Homi Bhabha e Stuart Hall estão inscritas em histórias particulares, na língua inglesa, em memórias de uma colonização distintas da "vivida" por outras partes do mundo como América Latina ${ }^{10}$. Aponta, por exemplo, o fato de que antes do orientalismo, plasmado ao longo dos séculos XIX e XX, houve um "ocidentalismo", com a Europa tentando dar sentido, a partir de suas referências, ao fato novo da "descoberta" (MIGNOLO, 2003, p. 89). Além de ficar atento ao espaço de fala que habita, podendo reproduzir o olhar ocidental, o intelectual, nessa perspectiva, não pode negar o espaço de onde fala, sua história específica, seu modo particular de se relacionar com a colonialidade. E, no caso de Mignolo, a "América Latina" é assumida como perspectiva epistêmica.

\section{Do intelectual Segundo Mignolo}

Já não bastasse a probabilidade da intelligentsia latino-americana poder experimentar os mesmos dilemas apontados por Gramsci, Mannheim e Bourdieu, refletindo sobre outros contextos, sua posição marginal e dependente das "luzes eurocêntricas", argumenta-se de forma semelhante aos pós-colonialismos, impõem novos dilemas. O problema para nós, intelectuais

\footnotetext{
${ }^{10}$ Afirma que, por exemplo, o "pós-colonial" refere-se às críticas realizadas em inglês a partir da Inglaterra ou das colônias de fala anglófona (Said, Bhabha etc). O autor alerta para o fato desse pensamento ter surgido no contexto pós-guerra fria e de libertação das colônias africanas, gerando uma dificuldade no emprego em outros contextos como o latino-americano. Nesse último, a ideia mestre, segundo Mignolo, é o "ocidentalismo" como alvo da crítica "pósocidental". Parte da mesma razão "subalterna" e do pensamento limiar que o pós-colonial, no entanto pelo fato da posição ambígua das "índias ocidentais" no imaginário Europeu e Americano; isso gerou uma outra figura histórica, que por sua vez deu origem a críticas outras. Ver o capítulo II do Histórias Locais/Projetos Globais (MIGNOLO, 2003).
} 
das margens do sistema-mundo, é que as modernidades não europeias são feitas da mistura particular de heranças e de rupturas traumáticas: da continuação da tradição cultural/histórica local, em sua polifonia de sentidos e experiências, e da mutação introduzida pelo "ocidente" 11 . Somos, desse ponto de vista, frutos do colonialismo, da modernização/ocidentalização (LECLERC, 2005). A perspectiva decolonial, ao projetar a existência de um saber negligenciado, exige o questionamento se tais intelectuais são traidores em relação à tradição local, apesar do papel importante que tiveram nas lutas de independência nacional, na construção das identidades e transmissão cultural. Aponta, também, para novas práticas intelectuais e teóricas capazes de superar os problemas vividos pelos intelectuais das "margens", especialmente no contexto latino-americano.

Conceber o mundo como discursivo ou abordar o social como fenômenos semióticos, permite Mignolo colocar em prática uma estratégia que valoriza o lugar e o papel dos saberes na articulação de relações de poder (ALCOFF, 2007, p. 80). Lida com "arquivos" retratados a partir de produtos culturais abstrato-eruditos, especialmente mapas, cartas, imagens diversas, que informam a natureza do mundo e do social, e estão inseridos em sistemas de significados que, quando atualizados, definem o modo como esse mundo se manifesta. Na perspectiva indisciplinada de Mignolo, ao procurar gerar liberações decoloniais, são privilegiados arquivos que expressam "desobediência epistêmica" (BASU \& JONG, 2016). É a comparação e descrição de jogos de linguagem expressos em livros, meio pelo qual procura projetar e compreender a conformação e as tensões da colonialidade que aparecem como suas principais fontes de reflexão e diálogo ${ }^{12}$. Daí a preocupação central com aqueles que surgem como meios e motores da afirmação das estruturas discursivas, contribuindo ou não para a cristalização de determinadas relações hierárquicas, privilégios e exclusões. A conceituação de Mignolo surge, assim, esboçando algo como uma "metáfora topográfica" (HULME, p. 229, 2009), em que pensadores, teóricos, filósofos, cientistas, em uma palavra, "intelectuais", podem ser imaginados como dispostos em lugares distintos de um território.

Se existe um antagonista nessa narrativa, o papel principal cabe ao Religioso, Filósofo ou Cientista que, localizados em terras distantes de uma geografia bárbara, formam, cada um a sua maneira, imagens deficitárias, autorreferidas e racistas do mundo. Mignolo indica que Bartolomeu de las Casas, com toda boa vontade, ao tentar justificar a humanidade do "índio", o

\footnotetext{
11 Um tipo de reflexão muito influenciada pela teoria da dependência (CARDOSO \& FALETTO, 2004), mas que trata da dimensão epistemológica.

12 Sobre a "dialética" ou a prática do "criticismo literário" levado a cabo pelo ironista, Rorty afirma "nós, ironistas, tratamos essas pessoas (outros filósofos) não como canais anônimos para a verdade, mas como abreviações para certos vocabulários finais e para crenças e desejos típicos daqueles que consomem essas ideias (...) tratamos os nomes dessas pessoas como os nomes dos heróis em seus livros" (RORTY, 1989, p. 79).
} 
fez a partir de "princípios teológicos do conhecimento", considerados superiores, inaugurando algo como uma tendência universalista do direito internacional (MIGNOLO, 2007, p. 43). Mas o padrão típico de interação entre os emissários de Roma e os grupos locais, analisado por Mignolo, é bem menos "cristão" do que o apresentado pelo debatedor de Valladolid. Vide, em outro lugar, o bispo Diogo de Landa (século XVI) que, com a imagem do "objeto livro" e uma interpretação cristã de sua função, levou a cabo uma "inquisição" que teve como uma de suas consequências a destruição de muitos códices maias (MIGNOLO, 1995, p. 71). Mal-entendido generalizado também presente na maneira como o franciscano Juan de Torquemada, de acordo com uma noção de história como construções narrativas em função do domínio da escrita alfabética, interpretou a ausência de história na cultura antiga mexicana (MIGNOLO, 1995, p. 128).

Em outro ponto de sua obra, Mignolo mostra que, séculos depois, a história do ponto de vista universal de Kant, ao esboçar uma categorização e uma hierarquização de povos e regiões, demonstra uma outra etapa desse pensamento arrogante (MIGNOLO, 2011, p. 163). Ao colocar uma raça, a branca europeia, como a única capaz de ter a "razão" plenamente desenvolvida, Kant, indica Mignolo, lança uma perspectiva etnocêntrica, exibindo um olhar racista que conformou mais uma etapa do grande "gesto de exclusão" do "Outro" que é a história do conhecimento ocidental. Imaginário linear também presente em Hegel que, norteado por sua história local, germânica, concebeu a evolução do "espírito" como traçando uma reta do oriente para o ocidente, seu ponto máximo. Tal "espírito", segundo Mignolo, era caracterizado segundo critérios definidos na comunidade intelectual do próprio Hegel tais como a organização de um Estado, a existência da individualidade e o secularismo, que funcionavam como parâmetros para avaliar o "grau de evolução" de outros povos, sempre em prejuízo desses últimos (MIGNOLO, 2012, p. XII). E assim o é com uma plêiade de "gigantes", representantes da tendência hegemônica do pensamento moderno, apequenados através da redescrição decolonial, que lhes apresenta como bairristas, cegos e inconsequentes em seu trabalho de manutenção de hegemonias epistêmicas.

Nesse cenário, um objeto de análise interessante para Mignolo são os cientistas sociais do "primeiro mundo" ou aqueles sujeitos do conhecimento que tinham o privilégio de ser "parte dos enunciados", mas os "únicos enunciadores" (MIGNOLO, 2011, p. 128). A partir do topos decolonial, Mignolo aponta, quase como um exemplo arquetípico, o modo como Weber concebe de forma endógena os processos que deram origem à modernidade, "entendida como a direção da história cujo objetivo e modelo era Europa" (MIGNOLO, 2007, p. 30). Afirma, assim, que o sociólogo alemão "estava cego para a diferença colonial e para subalternização do conhecimento nela embutida" (MIGNOLO, 2003, p. 24). Relata ainda que Giddens, em sua imagem elogiosa e linear da "modernidade", também estaria incluído no "paradigma teo e 
egopolítico do conhecimento" (MIGNOLO, 2007b, p. 465). E, para citar mais um dos grandes sociólogos, o "processo civilizador", obra-prima de Norbert Elias, é interpretada, por Mignolo, na chave de uma visão internalista e elogiosa da consolidação hegemônica da Europa, que se concentra tão somente no "arranjo temporal das histórias humanas implantadas na modernidade" (MIGNOLO, 2016, p. 416). A sociologia, nessa redescrição, aparece como uma das mais provincializadas disciplinas acadêmicas (!).

No entanto, até mesmo o intelectual crítico e militante, sempre herói cultural, não consegue escapar da reconversão de sentidos realizada por Mignolo, tornando-se algo como um trickster. Marx, o maior de todos, é retratado como elaborando uma rica teoria sobre o desenvolvimento do capitalismo que, não obstante a sua importância, refere-se a processos de mudança social e proletarização pertinentes a uma "classe social" enraizada no contexto europeu (MIGNOLO, 2011, p. 17). E apesar de assumir a autoridade de um ponto de vista universalista, procurando representar a experiência não europeia em seu esquema, não pôde enxergar os vínculos estreitos entre o desenvolvimento do capitalismo e a racialização dos povos e regiões. Mignolo indica que essa é uma dinâmica do sistema moderno/colonial que não poderia ser entendida por categorias como "proletariado", vinculada a projetos políticos e sociais pertencentes ao lugar de fala de Marx (MIGNOLO, 2005 p. 397). Faltaria ao autor do "O Capital", ainda preso da epistemologia moderna, segundo Mignolo, uma sensibilidade em relação ao "outro", à alteridade e à colonialidade (MIGNOLO, 2003, p. 245). Crítica que incluiria membros mais contemporâneos da tradição marxista tais como David Harvey, Michael Hardt e Anthony Negri (MIGNOLO, 2007B, p. 484).

O teórico decolonial mostra, desse modo, que as correntes contrahegemônicas podem atualizar um desprezo pela experiência não europeia que, apesar da visão positiva sobre seus feitos, não faria outra coisa do que contribuir para perpetuação do domínio colonial. Isso aparece em outros momentos como, por exemplo, na posição a um só tempo interessada e desobediente que Mignolo demonstra em relação ao projeto de teoria crítica da Escola de Frankfurt, especialmente a versão de Max Horkheimer. Mignolo diz preferir a nossa ideia de "liberação" à "emancipação" europeia (MIGNOLO, 2010, p. 100). É notável também na tentativa que faz de se apropriar da ideia de "subalterno" de Gramsci sob outra perspectiva, opondo aquele conceito, visto como vinculado a uma longa tradição de origem Greco-romana, ao de "damné", o subalterno decolonial (MIGNOLO, 2005). O alerta que lança tanto às esquerdas europeias como às latino americanas, que vêm lidando necessariamente com os fenômenos da transmodernidade e do pluralismo, também reflete essa crítica (MIGNOLO, 2011 p. 38). Em síntese, Mignolo aponta que a certeza que essas perspectivas têm de possuírem um insight teórico superior sobre a ordem e o destino do mundo, colocando-se como guias para a realização de determinados valores transcendentais pode, ao contrário 
do que se almeja, ajudar a perpetuar hierarquias, desprezos e violências epistêmicas.

Mas o drone teórico de Mignolo não para por aí. Embora não seja ferido mortalmente, devido a sua importância estratégica, o tipo intelectual de verniz pós-modernista, que ergue seu trabalho justamente como resposta às narrativas grandiloquentes e elogiosas da razão ocidental, também sofre com esse processo de redescrição. Apropriando-se da crítica ao universalismo de Nietzsche feita por Abdelkebir Khatibi, Mignolo indica que a luta do filósofo alemão contra o cristianismo, apesar da importância para os processos de libertação decolonial, é pertinente a um contexto Europeu (MIGNOLO, 2003, p. 101). Mesmo a desconstrução de Derrida ou a arqueologia foucaultina, ou seja, a "crítica interna à metafísica ocidental", careceriam do elemento decolonial. Para Mignolo, seus méritos se esgotam tendo em vista que não escapam da tendência a anunciar verdades como que aplicáveis a todo universo. Mignolo lembra, em outro contexto, que o apelo a "latinização do mundo", feito por Derrida, enquadra-se na imposição de uma visão universalista que resultou no abafamento das contribuições de índios e negros (MIGNOLO, 2007, p. 115). Seus métodos e soluções, apesar de inspiradores, precisavam passar por um processo de depuração realizado a partir da assunção da ideia de diferença colonial.

Mas, ao afastar-se dos "centros imperialistas", pode-se notar que o pensamento de Mignolo se concentra em pôr em evidência o terrível dilema da dependência estrutural, a nível do conhecimento, que sofrem intelectuais marginais devido a sua posição subalterna no mercado acadêmico e no debate informado ${ }^{13}$. O fato é que correriam o risco permanente de promover um "mimetismo" e um "colonialismo acadêmico" (MIGNOLO, 1993, p. 130), tomando objetos, conteúdos e necessidades concebidas em um contexto alheio, "metropolitano" e projetando sobre a realidade latino-americana uma representação míope que Quijano chamou de espejismo (QUIJANO, 2014, p. 644). Mignolo argumenta que essa estrutura fez com que, no século $X X$, intelectuais "crioulos", da envergadura do argentino Domingos Faustino Sarmiento e do brasileiro Euclides da Cunha, utilizassem o paradigma da "civilização" Vs. "natureza" para interpretar o atraso local vis-à-vis o outro lado do atlântico (MIGNOLO, 2007, p. 21). Juan Bautista Alberdi, intelectual e jurista argentino, seguiu a mesma linha eurofílica, esboçando uma compreensão histórica linear que, segundo Mignolo, acabou "reproduzindo uma genealogia de pensamento e formação subjetiva que era natural da historiografia europeia" (MIGNOLO, 2007, p. 100). Mas mesmo um intelectual contemporâneo como

\footnotetext{
${ }^{13}$ Perguntado sobre o fato de os intelectuais argentinos serem cosmopolitas, recebendo a crítica de "mentes colonizadas", Mignolo afirmou que não encontrava em seu país de origem "a inovação intelectual que oferecem certos setores de países andinos, a intelectualidade mexicana (incluídos os zapatistas), setores do equador (Luis Macas e o projeto de universidade intercultural, por exemplo) ". Acessado em 06/06/2018, no endereço: http://edant.clarin.com/suplementos/cultura/2002/05/18/u-00601.html
} 
Renato Ortiz, elaborador de uma importante teorização sobre a "mundialização", segundo Mignolo, se manteria vinculado a uma autoperpetuadora epistemologia moderna. Ortiz exibe, nesse enquadramento, os traços de "cegueira em relação à colonialidade", carecendo "da memória das diferenças e forças coloniais, ainda hoje atuantes" (MIGNOLO, 2003, p. 73).

A listagem dessa classificação esboçada por Mignolo parece nunca se exaurir. Esses "lugares exóticos" permanecem, em seu sistema teórico, como fundos potenciais de comparação, cuja negação permite aceder a outros espaços mais familiares (ou seriam todas versões de um espaço mais familiar?). Em uma fauna de conhecimentos diversos, em equilíbrio precário, Mignolo jamais decreta sua extinção completa, o fim de sua existência como alternativa plausível e risco permanente, ao pensar decolonial. $O$ fato é que categorias tais como "lugar de fala", "dualidade estrutural da história", "sistemamundo moderno/colonial", etc., permitem a Mignolo delinear manchas epistemológicas que possuem uma lógica de reprodução de poder que, apesar dos deslocamentos, apresenta caracteres discerníveis. Formam um fundo móvel, virtual, mas sempre disponível a ser recuperado como lugares fixos. É possível anexar, nesses pontos, práticas intelectuais desse ou daquele pensador cujas obras são objetos de interpretação depreciativa.

Na macronarrativa de Mignolo existe, em oposição a essa intelligentisia "profana", uma "sagrada". Refere-se a pensadores que, mesmo expostos à deglutição realizada pela hibris, produziram um "pensamento outro". É nesse sentido que Mignolo recupera a figura de Felipe Guaman Poma de Ayala como um dos que inauguram a crítica decolonizadora e o "paradigma da coexistência" (MIGNOLO, 2007, p. 136). Descreve o modo como esse indígena, que sofreu na pele o processo de destruição da cultura quechua, criou uma ideia de sociedade e imaginários espaciais peculiares: apesar de serem expressos em espanhol e levar em conta suas categorias, buscam restabelecer o direito epistêmico ao seu povo (MIGNOLO, 1995, p. 252). Da mesma linhagem que Poma de Ayala, Francisco de San Antón Muñón Chimalpaín, asteca que recebera uma educação europeia, segundo Mignolo, conseguiu traduzir o valor da oralidade e os significados da escrita em sua cultura, ao expressar-se em latim e nahuatl (MIGNOLO, 1995, p. 88). Essa "fratura" na "semiose colonial" é manifestada também na prática de Fernando de Alva Cortés Ixtlilxóchitl que, duvidando da interpretação da história mexicana dos espanhóis, em um gesto de desobediência epistêmica, valorizou fontes como os "livros pintados" mexicas, músicas e relatos orais (MIGNOLO, 1995, p. 93). 
Destacando-se diante daquele fundo negativo, estabelecido por Mignolo como uma darker side, casos como esses se avolumam em diversos pontos de sua teoria. Em outro contexto, citando um exemplo análogo, José Carlos Mariátegui aparece como marco importante na ruptura da "epistemologia do mesmo". Mignolo argumenta que esse autor realizou uma interpretação marxista retraduzida pela história e pela experiência peruana ameríndia. Isto é, pensou, com o auxílio de Marx e "a partir dos Andes", em uma indo-América (MIGNOLO 2003, p. 198), atualizando, no início do século XX, a prática da desobediência epistêmica (MIGNOLO, 2010, p. 92). Outro membro de uma vasta "genealogia" latino americana, a qual Mignolo diz se vincular é Quijano, dotado de uma perspectiva que está "enraizada na história e subjetividade colonial da América do Sul" (MIGNOLO, 2010, p. 77). Afirma que esse pensador ajudou a desvelar e integrar em uma nova interpretação "a face oculta da modernidade". Quijano, segundo Mignolo, ao ir além das categorias marxistas, demonstra os processos de classificação e hierarquização racial que ajudaram a fundamentar o surgimento do moderno sistema colonial (MIGNOLO, 2003, p. 288).

$\mathrm{O}$ recurso demonstrativo de Mignolo parece repetitivo. Um personagem tal como Rodolfo Kusch, argentino de origem alemã e de classe média, necessariamente tendo que atuar a partir da "tradição europeia", de sua filosofia, ao vincular-se aos "resquícios" da cultura dos povos originários, consegue, em um gesto rebeldia constituído a "partir das ruínas das categorias ameríndias", inaugurar um "outro pensamento" (MIGNOLO, 2003, p. 2009). Isso sugere que Mignolo, valendo-se de um esquema conceitual estabelecido no topos decolonial, absorve e acumula essas experiências, interpretando-as como paradigmáticas. Ou seja, delineadas a partir de seu caráter corrosivo em relação à colonialidade e expressas nas figuras desses pensadores, elas dão uma forma acentuada ao que se quer como um novo "lócus de enunciação", paradoxalmente, aberto, pluriversal. A estratégia reiterativa que se vê ao longo das obras de Mignolo assume, assim, um caráter didático: apresentar as boas práticas que esse tipo de pensador decolonial ensina e que podem servir de base a processos semelhantes de desenganchamento de povos e grupos que enfrentam os desafios colocados pela face mais atual da colonialidade. É aqui que entra a importância em retratar também casos análogos mais contemporâneos de desobediência epistêmica.

Assim o é com o que chama de intelectual local ou ativista (MIGNOLO, 2011, p. 58), tal como o Subcomandante Marcos, pensador de origem mexicana urbana e marxista, cujas atividades se deram no contato com um movimento indígena com uma longa tradição de luta e resistência. A ideia é que 0 intelectual zapatista realiza uma dupla tradução: do marxismo para a experiência local e da experiência local para o que está além, na nação mexicana, no mundo. Isso pressupõe, nos termos de Mignolo, um "risco" de ser transformado, de alterar a própria base cosmológica (MIGNOLO, 2011, p. 220). 
Rigoberta Menchú Tum, guatemalteca de origem quixé-maia, reconhecida por sua luta pelos direitos dos povos indígenas, é citada como exemplo de uma epistemologia limiar e não conotativa (MIGNOLO, 2003, p. 52). Mignolo enaltece o fato de que ela viveu vinte anos de sua vida em uma comunidade indígena de sua etnia, só tardiamente aprendendo o espanhol. Silvia Rivera Cusicanqui, socióloga e ativista de movimentos indígenas bolivianos, é outra que, além de fornecer insights teóricos importantes para compreender a dinâmica de uma colonialidade interna (MIGNOLO, 2003, p. 104), tem uma perspectiva de "investigação" que, de acordo com Mignolo, consegue ultrapassar os limites das ciências sociais. Sua história oral, para além de um método, subserviente às regras disciplinares, aparece como uma interação rica, transformadora, através do qual busca exprimir a visão de mundo e as necessidades do "outro", povos de origem quexua e aymara (MIGNOLO, 2001).

Mignolo argumenta que, de fato, "desde os anos 1970, intelectuais indígenas, na Colômbia, Equador e Bolívia" vêm praticando o que chama de "gnose limiar", "uma perspectiva que cresce dos legados e experiências coloniais" (MIGNOLO, 1997, p. 1140) em um contexto de confronto entre histórias locais e projetos globais. Contudo, esclarece, ao tratar de tais figuras não se refere a uma ideia de "organicidade" gramsciana (MIGNOLO, 2005). Diz preferir o termo "intelectual público", pois "a questão não se refere mais a um 'intelectual orgânico' de uma comunidade autônoma e isolada". Na verdade, envolveria "uma gnose limiar, na qual o intelectual indígena expressa a memória da nação em espanhol e nas línguas nativas" (MIGNOLO, 1997, p. 141). E apesar de perceber a diferença de estratégias, linguagem e práticas entre tais intelectuais "indígenas/ativistas" e "intelectuais acadêmicos", Mignolo afirma que "acadêmicos e ativistas não são necessariamente pessoas diferentes - os dois são frequentemente incorporados nas mesmas pessoas" (MIGNOLO, 2011, p. 58). A sua perspectiva, tendo em vista que Mignolo apresenta certas características que querem espelhar o modo elogiável como esse intelectual público atua, parece ser um exemplo dessa fusão.

Um dos pontos altos da argumentação de Mignolo é, portanto, o desarranjo dos modos tradicionais dos "intelectuais", aqueles que, nas palavras do pensador decolonial, "se destacam pela sua contribuição na articulação do imaginário de uma comunidade" (MIGNOLO, 1997, p. 1140), levarem a cabo seu ofício. Sua versão universal, "a partir das quais todas as outras possibilidades são definidas, medidas e subalternizadas" (MIGNOLO, 1997, p. 1140), é objeto de um desinvestimento teórico por parte do autor argentino. De uma forma similar que lida com outras instituições ocidentais, em sua estratégia de desobediência, Mignolo procura se desenganchar de uma compreensão de intelectual como significante vazio, vinculado à história 
ocidental, mas projetado indiscriminadamente em lugares distintos ${ }^{14}$. Isso o leva, por exemplo, a questionar os fundamentos da imagem de intelectual centrada no domínio do alfabeto, em línguas imperiais, o que negaria o papel da oralidade e das pessoas que assumiam a função de transmitir o conhecimento, edificar moralmente e reproduzir suas comunidades através de narrativas. Mas a consequência mais importante é propor uma nova interpretação a respeito do "intelectual", delineando os fundamentos mais adequados para sua atuação em um contexto de luta decolonial.

\section{Considerações finais}

Como observado na primeira parte desse artigo, a abordagem decolonial de Walter Mignolo sobre os intelectuais possibilita um esboço de "redescrição" e o apontamento de alguns limites existentes nas perspectivas usuais sobre os intelectuais. Em relação às "sociologias dos intelectuais" a crítica do autor argentino, com base na ideia da existência de um "eurocentrismo" de fundo, possibilita provincializar iniciativas como a de Gramsci e Mannheim: o primeiro falando a partir do sul da Itália, segundo uma reação a hegemonia capitalista, em busca de fortalecer o papel de "intelectuais orgânicos" ligados às classes populares daquele contexto; o segundo, inspirado pelo historicismo e na busca de corrigir os efeitos negativos do estilhaçamento de perspectivas trazidas pela modernidade europeia segundo a experiência alemã e o lugar dos intelectuais na produção de conhecimentos mais ou menos objetivos sobre a realidade. Foi possível indicar que tais contribuições além de adotarem 0 marco epistemológico e histórico da experiência europeia, possuíam um tom universalista que não levava em conta a experiência dos "intelectuais" surgidos nas margens do sistema-mundo moderno/colonial.

Bourdieu, como foi visto, apresenta uma perspectiva muito importante para a análise dos limites que a atuação do intelectual que apresenta um "habitus" específico. As contribuições de Connell permitiram, contudo, identificar uma série de traços nesse autor que também permitiram anexá-lo, de acordo com uma "geopolítica do conhecimento", no lugar reservado aos homens, europeus, com sua perspectiva plasmada dentro da experiência francesa. A radicalidade da crítica de Bourdieu, ao identificar uma um gosto condicionado apenas pelas necessidades nas classes populares, impede a observação de elementos potencialmente disruptivos na experiência, memória e utopias forjadas fora ou às margens da modernidade. Isso é uma faca de dois

\footnotetext{
${ }^{14}$ Mignolo usa o termo "intelectual" como um "conector", aludindo e buscando superar a noção de "significante vazio" de Ernesto Laclau (LACLAU, 1996, p. 36). Afirma "o que é necessário é a 'universalidade do conector' (sinais são nós de conexão, ao invés de significantes vazios, eles contêm vários projetos) que muda os termos da conversação e torna possível conceber e caminhar em direção a pluriversidade como projeto universal” (MIGNOLO, 2011, p. 230)
} 
gumes: de um lado, apresenta um antídoto a uma posição muito "populista" no que se refere à possibilidade de "organicidade" por parte dos intelectuais; do outro, corroí a possibilidade de um diálogo, ainda que precário, entre os intelectuais e grupos e movimentos sociais submetidos à colonialidade (variável ausente na intepretação do francês).

No que aqui foi etiquetado de pensamento "pós-moderno", a abordagem decolonial de Walter Mignolo assume a importância da ideia de um "giro linguístico", do foco no "discurso", "semiótica" e "desconstrução" em autores como Foucault, Nietzsche, Derrida, Deleuze e Guattari. No entanto, a "French theory" (CUSSET, 2005), apesar de contribuir para uma crítica da modernidade a partir de dentro da modernidade, também carrega alguns limites. Ao analisar a crise do conhecimento e do papel dos intelectuais na Europa, Lyotard não levou em conta a existência de outros contextos em que a herança das "grandes narrativas" europeias dialogavam com outras narrativas, memórias e histórias, trazendo problemas outros que não o enfrentando pelo campo de conhecimento ocidental. De acordo com Mignolo, o mesmo problema de cegueira em relação à colonialidade se daria em Nietzsche.

A ideia da existência de uma estrutura discursiva racista e hierarquizadora que ainda hoje condiciona a atividade dos "intelectuais", segundo o ponto de vista decolonial, exige a construção de mediações e adaptações em relação a essas e outras contribuições teóricas de origem eurocêntrica. Além da dinâmica de suas relações com grupos sociais, posições políticas mais tradicionais e limites de atuação em um contexto de ceticismo, o pensamento decolonial indica que estuda-los em contextos de países periféricos herdeiros da colonização, como o Brasil, exige interpretá-los sob a pressão de uma colonização intelectual que existe desde 0 inicio do colonialismo, apesar de apresentar diferente configurações. No mundo atual, segundo Martins, as pressões de um neoliberalismo econômico, em um contexto pós-colonial caracterizado por crises, superação das fronteiras geográficas e das identidades fixas, exige a atuação de um "intelectual tradutor", atuando em "zonas de contato" (MARTINS, 2012) com vistas a inaugurar "heterotopias". O pensamento decolonial ofereceria assim um novo instrumento heurístico para entender o papel das tão controvertidas figuras que são os intelectuais.

Mas tal perspectiva não é apenas uma "ferramenta" neutra para o estudo dos intelectuais. Um outro caminho apontado por Mignolo e por outros membros do grupo modernidade/colonialidade é um "giro decolonial" com consequências práticas para processos de liberação. Isso envolve uma crítica profunda, em vários níveis, da epistemologia moderna e a busca de uma "sociologia das emergências", a valorização das experiências silenciadas pela modernidade, e o reforço epistêmico, através de uma "sociologia das ausências", de outros potenciais existenciais. Mignolo indica que caberia a esse intelectual o papel de traduzir as necessidades e saberes locais em 
diálogo com outros conhecimentos tradicionais. E apesar de dizer que acadêmicos não se confundiriam com militantes e "intelectuais comunitários", os dois se confundem tanto na atuação quanto na defesa do valor político e moral da liberação dos damnés. Existe em Mignolo uma imagem axiológica bem-acabada do modo como tais intelectuais atuariam.

A questão que fica em aberto e sé o próprio autor conseguiu atualizar em sua prática esse ideal de "intelectual decolonial" que desenvolve. Algo que tem relação com as opções do autor de realizar uma "macronarrativa" (MIGNOLO, 2003, p.10) distanciada que, por um lado, fornece instrumentos teóricos muito importantes e consequentes em termos políticos, por outro não conseguiu desenvolver a tão exigida "organicidade" decolonial com os outros da colonialidade.

\section{REFERÊNCIAS}

ALCOFF, Linda Martín. Mignolo's epistemology of coloniality. In: The New Centennial Review, v. 7, n. 3, p. 79-101, 2007.

BASU, Paul; DE JONG, Ferdinand. Utopian archives, decolonial affordances Introduction to special issue. Social Anthropology, v. 24, n. 1, p. 5-19, 2016.

BERGER, Peter L.; LUCKMANN, Thomas. A construção social da realidade: tratado de sociologia do conhecimento. Petrópolis: Vozes, 2007.

BOURDIEU, Pierre. Os usos sociais da ciência: por uma sociologia clínica do campo científico. São Paulo: UNESP, 2004.

A distinção: crítica social do julgamento. Porto Alegre: Zouk, 2013.

CASTRO-GÓMEZ, Santiago. La hybris del punto cero: ciencia, raza e ilustración en la nueva Granada (1750-1816). Bogotá: Editorial Pontíficia universidade Javeriana, 2005.

CÉSAIRE, Aimér. Discurso sobre o colonialismo. Lisboa: Ed. Livraria Sá da Costa Editora,1978.

CONNELL, Raewyn. Northern theory: The political geography of general social theory. Theory and Society, v. 35, n. 2, p. 237-264, 2006.

CUSSET, François. French Theory: Foucault, Derrida, Deleuze \& Cie et les mutations de la vie intellectuelle aux États-Unis. Paris : La Découverte, 2005.

DEL ROIO, Marcos. Gramsci contra o ocidente, in: AGGIO, Alberto (ed.). Gramsci: a vitalidade de um pensamento. São Paulo: Unesp,1998. p. 103-121.

FANON, Frantz. Em defesa da revolução africana. Lisboa: Livraria Sá da Costa Editora, 1980.

Los condenados de la tierra. Mexico: FCE, 2001. 
Pele negras mascaras brancas. Salvador: EDUFBA, 2008.

FOUCAULT, Michel. Os intelectuais e o poder. Conversa entre Michel Foucault e Gilles Deleuze. In: Microfísica do poder. 4를 edição. Rio de Janeiro, Graal, 1979a. p. 69-78.

. Verdade e poder. Conversa entre Michel Foucault e Gilles Deleuze. In:

Microfísica do poder. 4ª edição. Rio de Janeiro, Graal, 1979b. p. 1-15.

Dits et Ecrits, 1954-1988. Tome III: 1976-1979. France: Editions Gallimard, p. 31-33, 1994.

As palavras e as coisas: uma arqueologia das ciências humanas. São Paulo: Martins Fontes, 2007

A arqueologia do saber. Rio de Janeiro: Forense Universitária, 2015.

FUREDI, Frank. Afterword: the downsizing of intellectual authority. Critical Review of International Social and Political Philosophy, v. 6, n. 4, p. 172-178, 2003.

GODIN, Louis-Daniel. 2014. Michel Foucault et la figure de l'intellectuel spécifique.

Figura. Montréal : Université du Québec à Montréal. Vol. 35, p. 169-188, 2014.

GRAMSCI, Antonio. Os intelectuais e a organização da cultura. Rio de Janeiro: Civilização Brasileira, 1989.

HALL, Stuart. The west and the rest: discourse and power. In: HALL \& GIEBEN (Ed.). Formations of modernity. Cambridge: Polity Press in association with the Open University, 1992, p. 275-331.

HEYES, Cressida, "Identity Politics". In: ZALTA, Edward N. The Stanford Encyclopedia of Philosophy. Spring 2018 Edition. Disponível em: <https://plato.stanford.edu/archives/spr2018/entries/identity-politics/>. Acesso em: 27 de fev. 2018.

HULME, Peter. Voice from the margins?: Walter mignolo's the darker side of the renaissance. Journal of Latin American Cultural Studies, v. 8, n. 2, p. 219-233, 1999.

JAMES, William. Pragmatism: A new name for some old philosophy, old ways of thinking: Popular lectures on philosophy. USA: Longmans, Green, 1921.

KARABEL, Jerome. Towards a theory of intellectuals and politics. Theory and Society. 25, p. 205-233, 1996.

KURZMAN, Charles; OWENS, Lynn. The sociology of intellectuals. Annual Review of Sociology, v. 28, n. 1, p. 63-90, 2002.

LECLERC, Gérard. Sociologia dos Intelectuais. Rio Grande do Sul: Editora Unisinos, 2005.

LYOTARD, Jean-François. A condição pós-moderna. Rio de Janeiro: José Olympio, 2009. 
MALDONADO-TORRES, Nelson. "Sobre la colonialidad del ser: contribuciones al desarrollo de un concepto". In: CASTRO-GOMEZ, Santiag; GROSFOGUEL, Ramon (ed.). El giro decolonial. Reflexicones para uma diversidad epistêmica más Allá del capitalismo global. Bogotá: Eesco-pensar-Siglo del Hombre Editores, 2007. p. 127169.

MANNHEIM, Karl. Ideologia e Utopia. Rio de Janeiro: Guanabara, 1986.

Sociologia da cultura. São Paulo: Perspectiva, 2013.

MARTINS, Paulo Henrique. Poscolonialidad y antiutilitarismo: desafíos de la teoría sociológica más allá de las fronteras Sur-Norte. Revista colombiana de sociología, 33(1), 15-44, 2010.

. Interrogando las fronteras del conocimiento sociológico: globalización, descolonización y don. Umbrales - Revista Del Postgrado en Ciencias del Desarrollo, v. 24, p. 251-270, 2012.

MERTON, Robert K. Ensaios de sociologia da ciência. São Paulo: Editora 34, 2013.

MIGNOLO, Walter D. Colonial and postcolonial discourse: cultural critique or academic colonialism? Latin American Research Review, v. 28, n. 3, p. 120-134, 1993.

The Darker Side of Renaissance: literacy, territoriality and colonization. United States of America: The University of Michigan Press, 1995.

. Intellectuals. In: LACAPRA, Dominick. Today, tomorrow: The intellectual in the academy and in society. PMLA-Publications of the Modern Language Association of America, v. 112, n. 5, p. 1140-1141, 1997.

. La Contribucíon de Xavier Albó y Silvia Rivera Cusicanqui a la reestrutcturación de las ciências sociales desde los Andes. Rev. Venez. de Econ. Y Ciencias Sociales, v. 7, n. 3, p. 175-195, 2001.

Histórias locais/ Projetos globais: colonialidade, saberes subalternos e pensamento limiar. Belo Horizonte: Editora UFMG, 2003. 2005.

. On subalterns and other agencies. Postcolonial Studies, v. 8, n. 4, p. 381-407,

La Idea de América Latina. Barcelona: Editorial Gedisa, 2007.

Delinking: The rhetoric of modernity, the logic of coloniality and the grammar of de-coloniality. Cultural studies, v. 21, n. 2-3, p. 449-514, 2007b.

Desobediencia epistémica. Retórica de la modernidad, lógica de la colonialidad y gramática de la descolonialidad. Buenos Aires: Ediciones del Signo, 2010.

The darker side of western modernity: global futures, decolonial options. Durhan \& London: Duke University Press, 2011.

Local histories/global designs: Coloniality, subaltern knowledges, and border thinking. Princeton University Press, 2012. 
Telar, n. 6, p. 7-38, 2016.

QUIJANO, Anibal. Cuestiones y horizontes. De la dependecia historic-estrutural a la colonialidade/decolonialidad del poder. Buenos Aires: CLACSO, 2014.

RIBEIRO, Renato Janine. O intelectual e seu outro: Foucault e Sartre. Tempo Social, v. 7, n. $1 / 2$, p. 163-173, 1995.

RODRIGUES, Léo Peixoto. Introdução à sociologia do conhecimento, da ciência e do conhecimento científico. Passo Fundo, RS: UPF Ed., 2005.

RORTY, Richard. Contingency, Irony and Solidarity. UK: Cambridge University Press, 1989.

SAID, Edward W. Representations of the intellectual: The 1993 reith lectures. Vintage Books, 1994.

Representações do intelectual: as conferências Reith de 1993. Editora Companhia das Letras, 2005.

Orientalismo: o oriente como invenção do Ocidente. São Paulo: Companhia das Letras, 2007.

Cultura e imperialismo. São Paulo: Companhia das Letras, 2011.

SANTOS, Boaventura de Sousa. Para além do pensamento abissal: das linhas globais a uma ecologia de saberes. Revista crítica de ciências sociais, n. 78, p. 3-46, 2007. $2010 a$

A gramática do tempo: para uma nova cultura política. São Paulo: Cortez, 